\title{
Intermolecular [2+2] Photocycloaddition of $\beta$-Nitrostyrenes to Olefins upon Irradiation with Visible Light
}

\author{
Lisa-Marie Mohr \\ Thorsten Bach* (D)
}

Department Chemie and Catalysis Research Center (CRC), Technische Universität München, 85747 Garching, Germany thorsten.bach@ch.tum.de

Dedicated to Victor Snieckus, a dear colleague and friend, on the occasion of his $80^{\text {th }}$ birthday

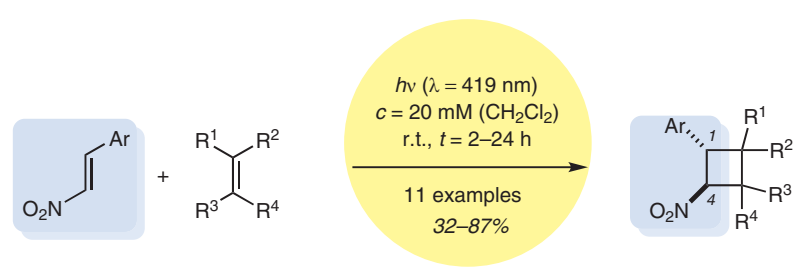

dergo direct intermolecular [2+2] photocycloaddition reaction upon excitation with visible light and we report in this communication on our preliminary results on this topic.

Already in the $19^{\text {th }}$ century, the $[2+2]$ photodimerization of trans- $\beta$-nitrostyrene was observed to occur upon exposure to sunlight. ${ }^{11}$ However, reactions with olefins in the spirit of an intermolecular [2+2] photocycloaddition have remained rare and were performed exclusively with short-wavelength light. Chapman et al. mentioned in a review on the photochemistry of unsaturated nitro compounds the reaction with olefins but did not provide any experimental details. ${ }^{12,13}$

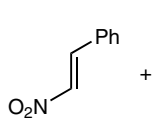

1

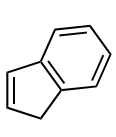

$2 a$

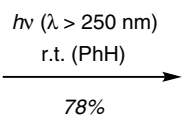

$78 \%$

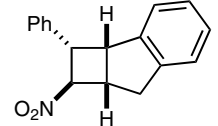
nates historically ${ }^{2}$ from experiments performed with visible light, the advent of artificial UV light sources led - starting in the middle of the $20^{\text {th }}$ century - to the almost exclusive use of short-wavelength $(\lambda=250-380 \mathrm{~nm})$ irradiation in all areas of photochemistry. Interest in reactions that were promoted by long-wavelength $(\lambda>380 \mathrm{~nm})$ irradiation was spurred in the 1970s and in the 1980s by the desire to find suitable energy storage systems mainly based on the [2+2] photocycloaddition of norbornadienes to quadricyclenes. $^{3}$ Aromatic carbonyl compounds ${ }^{4}$ and transition-metal salts ${ }^{5}$ were found to act as triplet sensitizers in this transformation allowing the reaction to occur with visible light. More recently, triplet energy sensitization has been employed for enantioselective ${ }^{6}[2+2]$ photocycloaddition reactions that are promoted by visible light ${ }^{7}$ in the presence of an appropriate sensitizer. ${ }^{8}$ In the context of our work on the activation of chromophors by Lewis or Brønsted acids, ${ }^{9}$ we became interested in the photochemistry of nitrostyrenes. ${ }^{10}$ The compound class seemed amenable to un-

Scheme 1 [2+2] Photocycloaddition of trans- $\beta$-nitrostyrene (1) and indene (2a) as reported by Majima et al. ${ }^{14}$

Later, Majima et al. employed the reaction of trans- $\beta$-nitrostyrene (1) and indene (2a) to form cyclobutane $\mathbf{3 a}$ (Scheme 1). ${ }^{14}$ A high-pressure mercury lamp was employed as the light source in this transformation. In more recent work, pyrex-filtered irradiation was used to study the reaction of nitrostyrenes with silyl enol ethers. ${ }^{15,16}$

Inspection of the UV-Vis spectrum ${ }^{17}$ of trans- $\beta$-nitrostyrene in $\mathrm{CH}_{2} \mathrm{Cl}_{2}$ (Figure 1) reveals a strong absorption centered at $\lambda=312 \mathrm{~nm}\left(\varepsilon=16500 \mathrm{M}^{-1} \mathrm{~cm}^{-1}\right)$. This band has been previously assigned to an allowed $\pi \pi^{*}$-transition with significant charge-transfer character. ${ }^{18,19}$ At high concentration it is evident that the absorption continues into the visible region of the electromagnetic spectrum in line with the fact that trans- $\beta$-nitrostyrene (1) is a yellow-colored solid. 


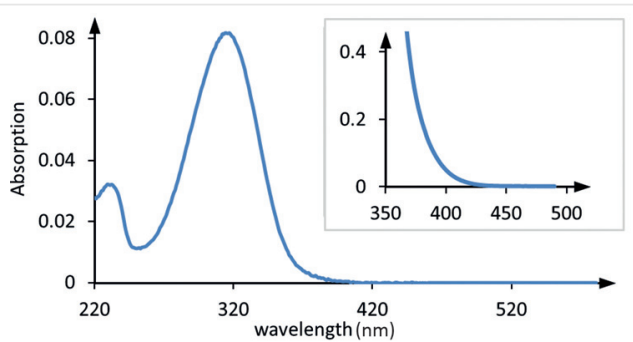

Figure 1 UV-Vis spectrum of trans- $\beta$-nitrostyrene in $\mathrm{CH}_{2} \mathrm{Cl}_{2}$ solution $(c=0.05 \mathrm{mM})$, the inset shows the long-wavelength absorption measured at $c=5 \mathrm{mM}$

In view of the apparent long-wavelength absorption of trans- $\beta$-nitrostyrene (1), its reaction with indene was revisited. The concentration, the solvent, and the stoichiometry (3.1 equiv indene) were taken from previous work, ${ }^{14}$ and the reaction was run for 23 hours (Table 1 ). We were pleased to find that conversion was not only complete when the mixture was irradiated with fluorescent lamps ${ }^{20}$ at $\lambda=300,350$, and $366 \mathrm{~nm}$, but also at $\lambda=419 \mathrm{~nm}$ (Table 1 , entries 1-4). In all cases, it was observed that major diastereoisomer 3a was accompanied by a minor diastereoisomer to which structure 3a' was assigned based on NOESY experiments. The diastereomeric ratio (d.r.) varied at around 3:1. Best yields were recorded at $\lambda=350 \mathrm{~nm}$ (Table 1, entry 2 ) and $\lambda=419 \mathrm{~nm}$ (Table 1, entry 4). Clearly, the [2+2] photocycloaddition was promoted by visible light as even longwavelength light-emitting diodes (LEDs) led to a significant conversion at $\lambda=457 \mathrm{~nm}$ and at $\lambda=470 \mathrm{~nm}$ (Table 1 , entries $5,6)$. At $\lambda=517 \mathrm{~nm}$, there was essentially no conversion after 23 hours (Table 1 , entry 7 ).

Table 1 Conversion, Yield, and Diastereomeric Ratio in the Intermolecular [2+2] Photocycloaddition Reaction to Products 3a/3a' in Correlation to the Irradiation Wavelength

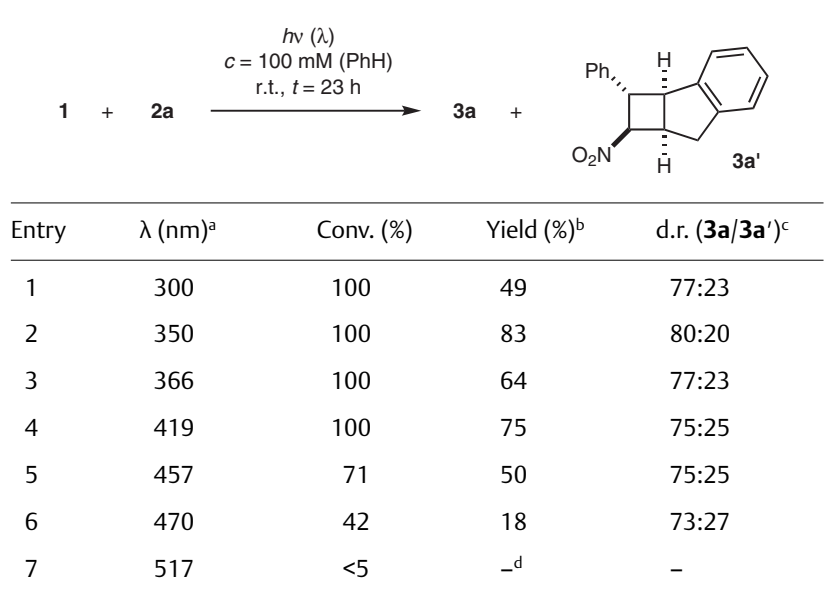

${ }^{\mathrm{a}}$ For the emission spectra of the light sources, see ref. ${ }^{20}$

' Yield of isolated products $3 \mathbf{a}$ and $\mathbf{3} \mathbf{a}^{\prime}$ as a mixture of diastereoisomers.

'The diastereomeric ratio (d.r.) was determined by integration of appropriate ${ }^{1} \mathrm{H}$ NMR signals.

${ }^{d}$ No significant amounts of the respective products were isolated.
Further experiments were undertaken to identify a less problematic solvent but benzene and to optimize the reaction conditions at $\lambda=419 \mathrm{~nm}$. While toluene was found less suited to substitute benzene, dichloromethane turned out to be an excellent solvent. A larger excess of the olefin led to higher product yields and the concentration was lowered to $20 \mathrm{mM}$ in order to allow for small-scale reactions with more precious, not commercially available nitrostyrenes (vide infra). At optimized conditions ${ }^{21}$ the $[2+2]$ photocycloaddition products $\mathbf{3 a} / \mathbf{3} \mathbf{a}^{\prime}$ were obtained in a yield of $87 \%$ after 24 hours of irradiation at $\lambda=419 \mathrm{~nm}$. A variety of other olefins was employed in the reaction, and the results are summarized in Scheme 2.

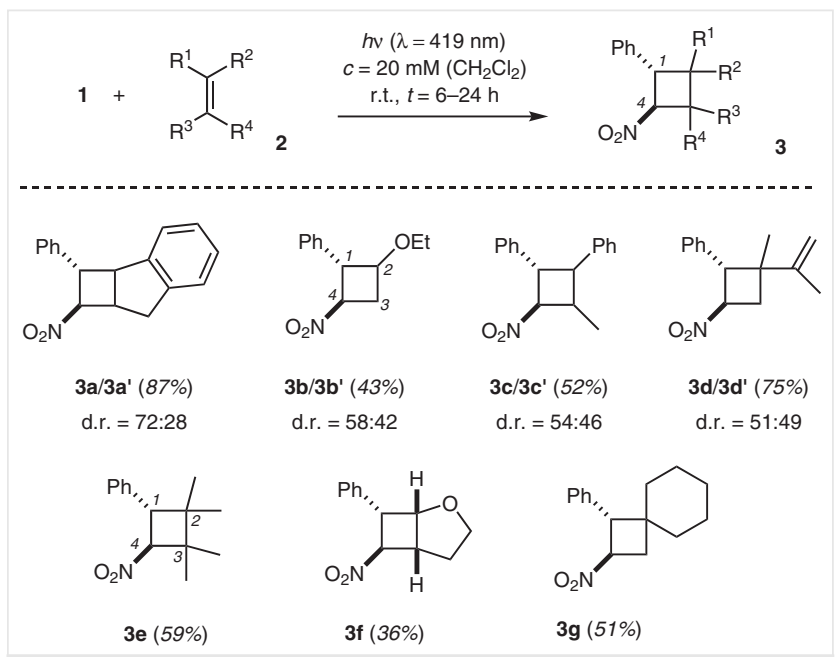

Scheme 2 Visible-light-induced [2+2] photocycloaddition of various olefins 2 to trans- $\beta$-nitrostyrene (1)

It should be noted that the reactions were not always complete and that in some cases substantial amounts (up to $22 \%$ ) of starting material were recovered, mostly as cis- $\beta$ nitrostyrene. Yields refer to isolated products, however, and are not corrected for conversion. With olefins $\mathbf{2 b}, \mathbf{d}, \mathbf{f}, \mathbf{g}$, the fact that the polarity of the excited state is opposite to the ground state polarity (photochemical umpolung) becomes particularly apparent. C-C bond formation occurs formally between two - in the ground state - electrophilic centers (C1-C2) and between two nucleophilic centers (C3-C4). The reactions with olefins $\mathbf{2 b}$-d led to a mixture of diastereoisomers the relative configuration of which could be in most cases elucidated by NOESY experiments (see Supporting Information for further details). Cyclobutanes $\mathbf{3 e - g}$ were obtained as single products. For the reaction of the electron rich olefin $\mathbf{2 b}$, it was checked that there was no reaction in the absence of irradiation. ${ }^{22}$

Contrary to unsaturated hydrocarbons $\mathbf{2 e}$ and $\mathbf{2 g}$, cyclopentene $\mathbf{2 h}$ did not react with a sufficient rate at $\lambda=419$ $\mathrm{nm}$. The [2+2] photocycloaddition could, however, be successively conducted if nitrostyrene $\mathbf{1}$ was irradiated in a 


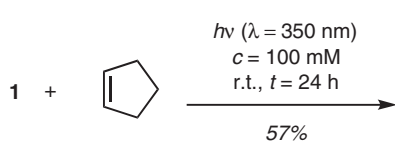

$2 \mathrm{~h}$

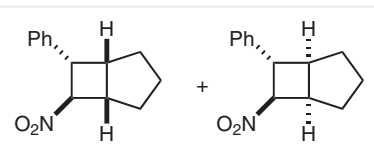

3h $\quad$ d.r. $=87: 13 \quad 3 h^{\prime}$
Scheme 3 Intermolecular [2+2] photocycloaddition of cyclopentene (2h) to trans- $\beta$-nitrostyrene (1)

solution of cyclopentene at $\lambda=350 \mathrm{~nm}$ (Scheme 3 ). The products were found to be a mixture of diastereoisomers in which product $\mathbf{3 h}$ with the nitro group in exo position to the cyclopentyl ring prevailed (d.r. =87:13).

Some preliminary experiments were conducted with other aromatic nitroolefins 4 (Scheme 4). 2,3-Dimethyl-2butene (2e) was employed as the reaction partner since its use avoids the formation of regio- or diastereomeric cyclobutane products. It was found that electron-rich aryl groups (para-tolyl, para-anisyl, 2-thiophenyl) in 2-position of the respective nitroethenes $\left(\mathbf{4} \mathbf{a},{ }^{23} \mathbf{4} \mathbf{b},,^{23} \mathbf{4} \mathbf{d}^{24}\right)$ led in their [2+2] photocycloaddition to results similar to those of trans- $\beta$-nitrostyrene. Reaction times were short $(2-4 \mathrm{~h})$ and cyclobutanes $\mathbf{5 a}, \mathbf{5 b}$, and $\mathbf{5 d}$ were obtained in yields of 50-54\%. The reaction with the para-cyano-substituted nitrostyrene $\mathbf{4} \mathbf{c}^{25}$ was less chemoselective and gave product $\mathbf{5 c}$ in a yield of only $32 \%$ after a longer reaction time $(6 \mathrm{~h})$. A side product could be isolated (vide infra).
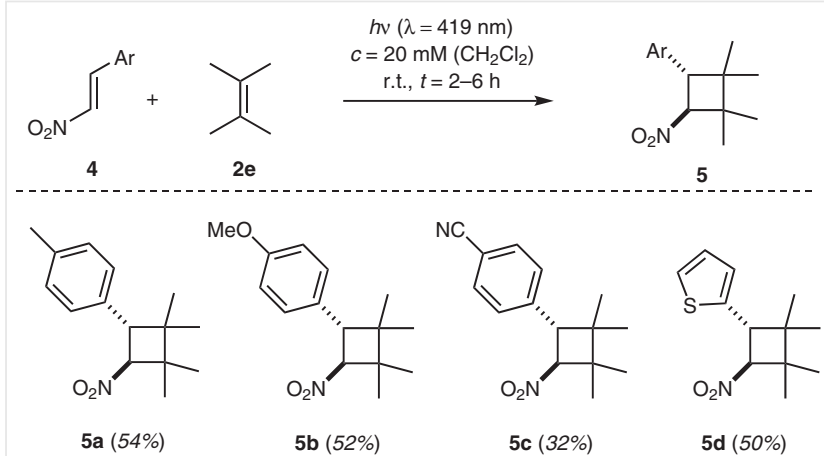

5 c $(32 \%)$

$5 d(50 \%)$

Scheme 4 Visible-light-induced [2+2] photocycloaddition of some 2aryl-substituted nitroethenes $\mathbf{4}$ and 2,3-dimethyl-2-butene (2e)

If 2,3-dimethyl-2-butene was subjected to [2+2] photocycloaddition with cis- $\beta$-nitrostyrene instead of trans- $\beta$-nitrostyrene the reaction was slower. The reaction product was exclusively the trans-substituted cyclobutane $\mathbf{3 e}$ that was isolated in $43 \%$ yield. Irradiation of trans- $\beta$-nitrostyrene at $\lambda=419 \mathrm{~nm}$ in the absence of an olefin established an equilibrium ${ }^{26}$ between the cis and the trans diastereoisomer in a ratio of $86: 14 .{ }^{27}$ This finding is in accord with the higher extinction coefficient of the trans diastereoisomer within the wavelength range of the light source. ${ }^{20 c}$ The absorption maximum of cis- $\beta$-nitrostyrene is centered at $\lambda=$ $309 \mathrm{~nm}\left(\varepsilon=5200 \mathrm{M}^{-1} \mathrm{~cm}^{-1}\right)$ in $\mathrm{CH}_{2} \mathrm{Cl}_{2}$ solution. ${ }^{26 \mathrm{~b}}$
Mechanistically, there is no indication for a reaction course which would deviate from the pathway of typical [2+2] photocycloaddition reactions. ${ }^{1}$ In this regard, it seems likely that olefin 2 adds to the excited substrate, for example, trans- $\beta$-nitrostyrene (1), most likely on the triplet hypersurface (Scheme 5). A 1,4-diradical $\mathbf{6}$ is formed as intermediate which collapses after intersystem crossing to product 3. Evidence for the postulated structure of diradical $\mathbf{6}$ is based on the constitution of the products and side products. Indeed, olefins such as $\mathbf{8}$ were isolated in a few instances and their formation is readily explained by a hydrogen abstraction in the intermediate 1,4-diradical. In the reaction of olefin $\mathbf{2 e}$ with styrene $\mathbf{4 c}$, byproduct $\mathbf{8}$ was obtained in $5 \%$ yield and is putatively formed via intermediate 7.

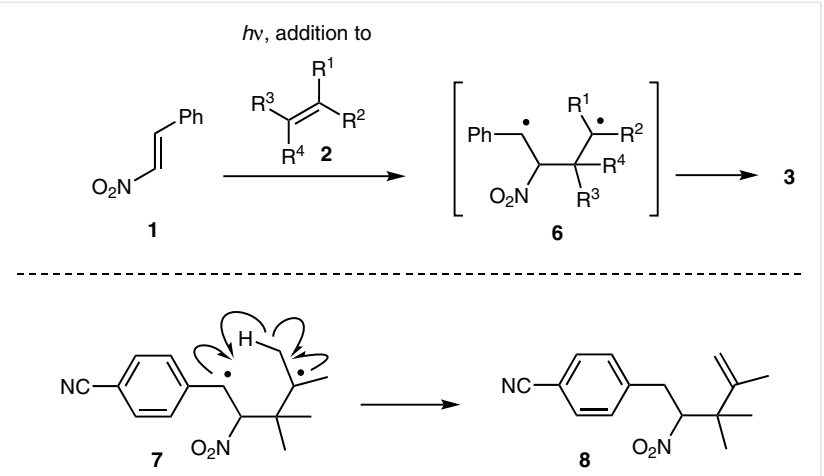

Scheme 5 Mechanistic suggestion for the reaction of trans- $\beta$-nitrostyrene (1) with olefins $\mathbf{2}$ via triplet 1,4-diradical $\mathbf{6}$ and formation of side product $\mathbf{8}$ in the reaction between $\mathbf{4 c}$ and $\mathbf{2 e}$ via 1,4-diradical $\mathbf{7}$

Further support for the hypothesis that the reaction proceeds via a triplet intermediate was obtained from the reaction of styrene $\mathbf{1}$ and olefin $\mathbf{2 e}$. In the absence of an additive the reaction was complete after 12 hours (Scheme 2 ), while a significant rate increase was noted upon addition of the triplet sensitizer 9H-thioxanthen-9-one (thioxanthone). ${ }^{28}$ No $\beta$-nitrostyrene was detected after three hours and product 3e was obtained in $47 \%$ yield (Scheme 6 ).

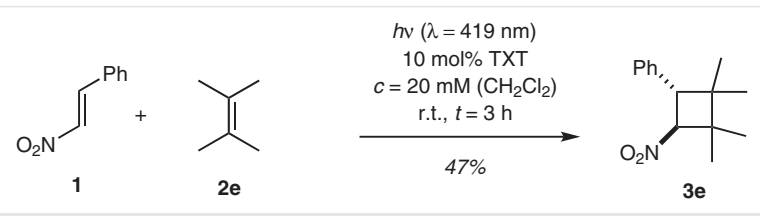

Scheme 6 Rate increase of the reaction between trans- $\beta$-nitrostyrene (1) and $\mathbf{2 e}$ in the presence of a triplet sensitizer (TXT = thioxanthone)

In summary, we have shown that nitro-substituted cyclobutanes can be accessed by a visible-light-induced [2+2] photocycloaddition of various 2-arylnitroethenes and olefins. The yields are moderate to good (32-87\%) and can possibly be further improved by adjusting the wavelength and the reaction temperature. Given the straightforward reduc- 
tion of nitro compounds to amines, ${ }^{11 c, 14,29}$ the method offers also access to various aminocyclobutanes. Mechanistically, it remains open to what degree a charge transfer ${ }^{30}$ occurs upon encounter of the photoexcited nitro compound and the olefin. In addition, it might be worth to study whether other nitroethenes but nitrostyrenes are equally suited for $[2+2]$ photocycloaddition reactions. Work along these lines is in progress in our laboratories and will be reported in due course.

\section{Funding Information}

Financial support by the European Research Council under the European Union's Horizon 2020 research and innovation programme (grant agreement No 665951 - ELICOS) is gratefully acknowledged.

\section{Supporting Information}

Supporting information for this article is available online at https://doi.org/10.1055/s-0036-1588524.

\section{Primary Data}

Primary data for this article are available online at https://zenodo.org/record/4610511 and can be cited using the following DOI: $10.5281 /$ zenodo.4610511. Please note that the DOI for the Primary Data associated with this article was updated on April 20, 2021.

\section{References and Notes}

(1) Poplata, S.; Tröster, A.; Zou, Y.-Q.; Bach, T. Chem. Rev. 2016, 116, 9748.

(2) Roth, H. D. Angew. Chem., Int. Ed. Engl. 1989, 28, 1193.

(3) (a) Lennartson, A.; Roffey, A.; Moth-Poulsen, K. Tetrahedron Lett. 2015, 56, 1457. (b) Dubonosov, A. D.; Bren, V. A.; Chernoivanov, V. A. Russ. Chem. Rev. 2002, 71, 917.

(4) (a) Barwise, A. J. G.; Gorman, A. A.; Leyland, R. L.; Smith, P. G.; Rodgers, M. A. J. J. Am. Chem. Soc. 1978, 100, 1814. (b) Jones, G. II.; Chiang, S.-H.; Xuan, P. T. J. Photochem. 1979, 10, 1.

(5) (a) Ikezawa, H.; Kutal, C.; Yasufuku, K.; Yamazaki, H. J. Am. Chem. Soc. 1986, 108, 1589. (b) Grutsch, P. A.; Kutal, C. J. Am. Chem. Soc. 1986, 108, 3108. (c) Sluggett, G. W.; Turro, N. J.; Roth, H. D. J. Phys. Chem. A 1997, 101, 8834.

(6) (a) Brimioulle, R.; Lenhart, D.; Maturi, M. M.; Bach, T. Angew. Chem. Int. Ed. 2015, 54, 3872. (b) Meggers, E. Chem. Commun. 2015, 51, 3290.

(7) (a) Zou, Y.-Q.; Duan, S.-W.; Meng, X.-G.; Hu, X.-Q.; Gao, S.; Chen, J.-R.; Xiao, W.-J. Tetrahedron 2012, 68, 6914. (b) Lu, Z.; Yoon, T. P. Angew. Chem. Int. Ed. 2012, 51, 10329. (c) Kumarasamy, E.; Raghunathan, R.; Jockusch, S.; Ugrinov, A.; Sivaguru, J. J. Am. Chem. Soc. 2014, 136, 8729. (d) Hurtley, A. E.; Lu, Z.; Yoon, T. P. Angew. Chem. Int. Ed. 2014, 53, 8991. (e) Liu, Q.; Zhu, F.-P.; Jin, X.-L.; Wang, X.-J.; Chen, H.; Wu, L.-Z. Chem. Eur. J. 2015, 21, 10326. (f) Mojr, V.; Svobodová, E.; Straková, K.; Neveselý, T.; Chudoba, J.; Dvořáková, H.; Cibulka, R. Chem. Commun. 2015, 51, 12036.
(8) (a) Alonso, R.; Bach, T. Angew. Chem. Int. Ed. 2014, 53, 4368. (b) Tröster, A.; Alonso, R.; Bauer, A.; Bach, T. J. Am. Chem. Soc. 2016, 138, 7808. (c) Blum, T. R.; Miller, Z. D.; Bates, D. M.; Guzei, I. A.; Yoon, T. P. Science 2016, 354, 1391.

(9) (a) Guo, H.; Herdtweck, E.; Bach, T. Angew. Chem. Int. Ed. 2010, 49, 7782. (b) Brimioulle, R.; Bach, T. Science 2013, 342, 840. (c) Brimioulle, R.; Bauer, A.; Bach, T. J. Am. Chem. Soc. 2015, 137, 5170. (d) Brenninger, C.; Pöthig, A.; Bach, T. Angew. Chem. Int. Ed. 2017, 56, 4337.

(10) Reviews on the photochemistry of nitro compounds: (a) Ho, T.I.; Chow, Y. L. Photochemistry of Nitro and Nitroso Compounds, In The Chemistry of Functional Groups, Supplement F2: The Chemistry of Amino, Nitroso, Nitro and Related Groups; Patai, S., Ed.; Wiley: Chichester, 1996, 747. (b) Döpp, D. Photochemical Reactivity of the Nitro Group, In CRC Handbook of Organic Photochemistry and Photobiology; Horspool, W. M.; Song, P.-S., Eds.; CRC Press: Boca Raton, 1995, 1019.

(11) (a) Priebs, B. Justus Liebigs Ann. Chem. 1884, 225, 319. (b) Meisenheimer, J.; Heim, F. Justus Liebigs Ann. Chem. 1907, 355, 260. (c) Miller, D. B.; Flanagan, P. W.; Shechter, H. J. Am. Chem. Soc. 1972, 94, 3912.

(12) Chapman, O. L.; Griswold, A. A.; Hoganson, E.; Lenz, G.; Reasoner, J. Pure Appl. Chem. 1964, 9, 585.

(13) In a later paper, the reaction of trans- $\beta$-nitrostyrene (1) and 2,3dimethylbutadiene (2d) was reported to be performed at $\lambda=$ 300 nm: Magner, J. T.; Selke, M.; Russell, A. A.; Chapman, O. L. J. Chem. Ed. 1996, 73, 854.

(14) Majima, T.; Pac, C.; Sakurai, H. J. Am. Chem. Soc. 1980, 102, 5265.

(15) Ramkumar, D.; Sankararaman, S. J. Chem. Soc., Perkin Trans. 2 1996, 939.

(16) For a Cr-photocatalytic [4+2] cycloaddition of trans- $\beta$-nitropara-methoxystyrene and 1,3-dienes, see: Stevenson, S. M.; Higgins, R. F.; Shores, M. P.; Ferreira, E. M. Chem. Sci. 2017, 8, 654.

(17) (a) Cheng, L. T.; Tam, W.; Marder, S. R.; Stiegman, A. E.; Rikken, G.; Spangler, C. W. J. Phys. Chem. 1991, 95, 10643. (b) Aboskalova, N. I.; Smirnova, N. N.; Kataeva, O. N.; Baichurin, R. I.; Fel'gendler, A. V.; Berkova, G. A.; Berestovitskaya, V. A. Russ. J. Gen. Chem. 2008, 78, 1711.

(18) (a) Cowley, D. J. J. Chem. Soc., Perkin Trans. 2 1975, 1576. (b) Zhang, S.-Q.; Wang, H.-G.; Pei, K.-M.; Zheng, X. J. Chem. Phys. 2007, 126, 194505.

(19) For further references to the photochemistry of nitroolefins, see: (a) Ried, W.; Wilk, M. Justus Liebigs Ann. Chem. 1954, 590, 111. (b) Zimmerman, H. E.; Roberts, L. C.; Arnold, R.J. Org. Chem. 1977, 42, 621. (c) Humphry-Baker, R. A.; Salisbury, K.; Wood, G. P. J. Chem. Soc., Perkin Trans. 2 1978, 659. (d) Grant, R. D.; Pinhey, J. T.; Rizzardo, E.; Smith, G. C. Aust. J. Chem. 1985, 38, 1505. (e) Kassaee, M. Z.; Nassari, M. A. J. Photochem. Photobiol. A 2000, 136, 41.

(20) For the emission spectra of the lamps, see for $\lambda=300 \mathrm{~nm}, 366$ nm: (a) Maturi, M. M.; Wenninger, M.; Alonso, R.; Bauer, A.; Pöthig, A.; Riedle, E.; Bach, T. Chem. Eur. J. 2013, 19, 7461. $\lambda=$ 350 nm: (b) Rimböck, K.-H.; Pöthig, A.; Bach, T. Synthesis 2015, 47, 2869. $\lambda=419 \mathrm{~nm}$ : (c) Alonso, R.; Bach, T. Angew. Chem. Int. Ed. 2014, 53, 4368. $\lambda=457$ nm, 470 nm: (d) Lenhart, D.; Bauer, A.; Pöthig, A.; Bach, T. Chem. Eur. J. 2016, 22, 6519.

(21) Representative Procedure

$29.8 \mathrm{mg}$ of nitrostyrene $\mathbf{1}$ ( $199 \mu \mathrm{mol}, 1.00$ equiv) and 10.0 equiv of olefin $2 \mathbf{e}(168 \mathrm{mg}, 2.00 \mathrm{mmol})$ were dissolved in degassed, dry $\mathrm{CH}_{2} \mathrm{Cl}_{2}(c=20 \mathrm{mM})$. The reaction solution was irradiated at 
$\lambda=419 \mathrm{~nm}$ in a Duran tube at r.t., and the reaction progress was monitored by TLC. When no further conversion was observed by TLC $(t=12 \mathrm{~h})$, the reaction was stopped and all volatiles were removed. Purification by column chromatography (pentane $\left./ \mathrm{Et}_{2} \mathrm{O}=20: 1\right)$ gave product $3 \mathrm{e}$ as a yellow oil $(27.5 \mathrm{mg}, 118$ $\mu \mathrm{mol}, 59 \%)$. When performed on a mmol scale (150 mg 1), product 3e was obtained in 56\% yield (132 mg). ${ }^{1} \mathrm{H}$ NMR (500 $\left.\mathrm{MHz}, \mathrm{CDCl}_{3}, 300 \mathrm{~K}\right): \delta=0.71\left(\mathrm{~s}, 3 \mathrm{H}, \mathrm{CH}_{3}-2\right), 1.15\left(\mathrm{~s}, 3 \mathrm{H}, \mathrm{CH}_{3}-3\right)$, $1.19\left(\mathrm{~s}, 3 \mathrm{H}, \mathrm{CH}_{3}-2\right), 1.24\left(\mathrm{~s}, 3 \mathrm{H}, \mathrm{CH}_{3}-3\right), 3.97\left(\mathrm{~d},{ }^{3} \mathrm{~J}=10.1 \mathrm{~Hz}, 1 \mathrm{H}\right.$, $\mathrm{H}-1), 4.91\left(\mathrm{~d},{ }^{3} \mathrm{~J}=10.1 \mathrm{~Hz}, 1 \mathrm{H}, \mathrm{H}-4\right), 7.08-7.13(\mathrm{~m}, 2 \mathrm{H}$, ortho$\left.\mathrm{H}_{\mathrm{Ar}}\right), 7.23-7.28\left(\mathrm{~m}, 1 \mathrm{H}\right.$, para $\left.-\mathrm{H}_{\mathrm{Ar}}\right), 7.30-7.37\left(\mathrm{~m}, 2 \mathrm{H}\right.$, meta- $\left.\mathrm{H}_{\mathrm{Ar}}\right)$ ppm. ${ }^{13} \mathrm{C}$ NMR ( $\left.101 \mathrm{MHz}, \mathrm{CDCl}_{3}, 300 \mathrm{~K}\right): \delta=19.5\left(\mathrm{q}, \mathrm{CH}_{3}-3\right), 21.5$ (q, $\mathrm{CH}_{3}-2$ ), 22.8 (q, $\left.\mathrm{CH}_{3}-3\right), 24.3$ (q, $\left.\mathrm{CH}_{3}-2\right), 39.3$ (s, C-2), 44.9 (s, C-3), 49.4 (d, C-1), 84.9 (d, C-4), 127.0 (ortho- $\left.\mathrm{C}_{\mathrm{Ar}} \mathrm{H}\right) .127 .1$ (d, para $\left.-\mathrm{C}_{\mathrm{Ar}} \mathrm{H}\right), 128.6\left(\mathrm{~d}\right.$, meta- $\left.\mathrm{C}_{\mathrm{Ar}} \mathrm{H}\right), 136.4\left(\mathrm{~s}, \mathrm{C}_{\mathrm{Ar}}\right) \mathrm{ppm}$.

(22) For thermal [2+2] cycloaddition reactions of trans- $\beta$-nitrostyrene (1) and olefins, see: (a) Brannock, K. C.; Bell, A.; Burpitt, R. D.; Kelly, C. A. J. Org. Chem. 1964, 29, 801. (b) Scheeren, H. W.; Frissen, A. E. Synthesis 1983, 794. (c) Albrecht, Ł.; Dickmeiss, G.; Acosta, F. C.; Rodríguez-Escrich, C.; Davis, R. L.; Jørgensen, K. A. J. Am. Chem. Soc. 2012, 134, 2543. (d) Seebach, D.; Sun, X.; Ebert, M.-O.; Schweizer, W. B.; Purkayastha, N.; Beck, A. K.;
Duschmalé, J.; Wennemers, H.; Mukaiyama, T.; Benohoud, M.; Hayashi, Y.; Reiher, M. Helv. Chim. Acta 2013, 96, 799. (e) Dobi, Z.; Holczbauer, T.; Soós, T. Eur. J. Org. Chem. 2017, 1391.

(23) Yan, Q.; Liu, M.; Kong, D.; Zi, G.; Hou, G. Chem. Commun. 2014, 50,12870

(24) Quan, X.-J.; Ren, Z.-H.; Wang, Y.-Y.; Guan, Z.-H. Org. Lett. 2014, $16,5728$.

(25) Keene, C.; Kürti, L. Synthesis 2013, 45, 1719.

(26) (a) Bluhm, A. L.; Weinstein, J. J. Am. Chem. Soc. 1965, 87, 5511. (b) Miller, D. B.; Flanagan, P. W.; Shechter, H.J. Org. Chem. 1976, 41, 2112. (c) Desiraju, G. R.; Pedireddi, V. R. J. Chem. Soc., Chem. Commun. 1989, 1112.

(27) The reaction time was $6 \mathrm{~h}$. If the isomerization was performed starting from cis- $\beta$-nitrostyrene under otherwise identical conditions, the cis/trans ratio was 82:18.

(28) The tabulated triplet energy $\left(E_{T}\right)$ of thioxanthone is $E_{T}=265 \mathrm{~kJ}$ $\mathrm{mol}^{-1}$ : Murov, S. L.; Carmichael, I.; Hug, G. L. Handbook of Photochemistry, 2nd ed.; Marcel Dekker: New York, 1993, 80.

(29) Xiong, H.; Foulk, M.; Aschenbrenner, L.; Fan, J.; Tiong-Yip, C.-L.; Johnson, K. D.; Moustakas, D.; Fleming, P. R.; Brown, D. G.; Zhang, M.; Ferguson, D.; Wu, D.; Yu, Q. Bioorg. Med. Chem. Lett. 2013, 23, 6789 .

(30) (a) Müller, F.; Mattay, J. Chem. Rev. 1993, 93, 99. (b) Mori, T.; Inoue, Y. Chem. Soc. Rev. 2013, 42, 8122. 